\title{
Article
}

\section{Potential use of PCSK9 inhibitors as a secondary preventative measure for cardiovascular disease following acute coronary syndrome: a UK real-world study}

Elamin, Ahmed Farouk Mohamed, Grafton-Clarke, Ciaran, Wen Chen, Kai, Obafemi, Toba, Luvai, Ahai, Katira, Ravish and Davis, Gershan

Available at https://clok.uclan.ac.uk/26101/

Elamin, Ahmed Farouk Mohamed, Grafton-Clarke, Ciaran, Wen Chen, Kai, Obafemi, Toba, Luvai, Ahai, Katira, Ravish and Davis, Gershan orcid iconORCID: 0000-0001-9096-5495 (2019) Potential use of PCSK9 inhibitors as a secondary preventative measure for cardiovascular disease following acute coronary syndrome: a UK real-world study. Postgraduate Medical Journal, 95 (1120). ISSN 0032-5473

It is advisable to refer to the publisher's version if you intend to cite from the work. http://dx.doi.org/10.1136/postgradmedj-2018-136171

For more information about UCLan's research in this area go to http://www.uclan.ac.uk/researchgroups/ and search for <name of research Group>.

For information about Research generally at UCLan please go to http://www.uclan.ac.uk/research/

All outputs in CLoK are protected by Intellectual Property Rights law, including Copyright law. Copyright, IPR and Moral Rights for the works on this site are retained by the individual authors and/or other copyright owners. Terms and conditions for use of this material are defined in the policies page. 
Title: Potential use of PCSK9 inhibitors as a secondary preventative measure for cardiovascular disease following acute coronary syndrome; a UK Real World study.

Authors: Ahmed Elamin ${ }^{1,4}$, Ciaran Grafton-Clarke ${ }^{2}$, Kai Wen Chen $^{2}$, Toba Obafemi ${ }^{1}$, Ahai Luvai $^{3}$ Ravish Katira ${ }^{4}$, Gershan Davis ${ }^{5}$

${ }^{1}$ Aintree Cardiac Centre, University Hospital Aintree, Liverpool, UK, ${ }^{2}$ School of Medicine, University of Liverpool, Liverpool, UK, ${ }^{3}$ The Newcastle upon Tyne Hospitals NHS

Foundation Trust, Newcastle, UK, ${ }^{4}$ Whiston Hospital, Prescott, Merseyside, UK, ${ }^{5}$ School of Medicine, University of Central Lancashire, Preston, UK

Financial support: Nil to declare.

Disclaimers: Nil to declare.

\section{Corresponding author:}

Professor Gershan Davis

Academic Cardiovascular Group

School of Medicine

University of Central Lancashire

Preston

PR1 2HE

UK

E Mail: gdavis1@uclan.ac.uk

Telephone 00447796944715 


\section{Word count (excluding references): 2897}

The Corresponding Author has the right to grant on behalf of all authors and does grant on behalf of all authors, a worldwide licence to the Publishers and its licensees in perpetuity, in all forms, formats and media (whether known now or created in the future), to i) publish, reproduce, distribute, display and store the Contribution, ii) translate the Contribution into other languages, create adaptations, reprints, include within collections and create summaries, extracts and/or, abstracts of the Contribution, iii) create any other derivative work(s) based on the Contribution, iv) to exploit all subsidiary rights in the Contribution, v) the inclusion of electronic links from the Contribution to third party material where-ever it may be located; and, vi) licence any third party to do any or all of the above. 


\begin{abstract}
Background: Proprotein convertase subtilisin/kexin type 9 (PCSK9) inhibitors are a major development in the prevention of cardiovascular disease (CVD) and is one of the most significant discoveries since the development of statin therapy. Administration of two human monoclonal antibodies to PCSK9 (alirocumab and evolocumab) can significantly reduce LDLc concentrations thus improving lipid management. Accordingly, guidelines on the specific indications for alirocumab and evolocumab usage have been released. This multi-centre study aimed to estimate the proportion of patients treated for an acute myocardial infarction who could be considered for PCSK9 inhibitors under current National Institute for Health and Care Excellence (NICE) lipid targets criteria.
\end{abstract}

Methods: The records of 596 patients in two large hospitals in Liverpool, UK were analysed. Information was collected on lipid profiles during and after admission, lipid-lowering therapy and previous CVD.

Results: At least $2.2 \%$ of patients were eligible for PCSK9 inhibitors post-MI under current NICE guidance. Additionally, $29 \%$ of patients failed to achieve LDL-c concentrations $<2.0$ $\mathrm{mmol} / \mathrm{L}$ despite maximum statin therapy, and failed to meet eligibility for PCSK9 inhibitors as per NICE criteria. This cohort represents a group of patients "in limbo', in which statin therapy alone is not sufficient to reduce LDL-c.

Conclusions: PCSK9 inhibitors are expensive and so their use must be highly selective. At present, in a real world setting with ezetimibe under-prescribing, $2 \%$ of patients are eligible and a further $30 \%$ are deprived of benefit and improved outcomes by lack of optimisation and/or potential use of pcsk9 inhibitors.

Abstract word count: 274 words 
Keywords: PCSK9 inhibitors; cardiovascular disease; secondary prevention; acute coronary syndrome; lipids; cholesterol. 


\section{INTRODUCTION}

There is strong and consistent evidence from genetic studies, prospective epidemiologic cohort studies and randomised trials that a log-linear relationship exists between low-density lipoprotein cholesterol (LDL-c) concentrations and the risk of cardiovascular disease (CVD). ${ }^{1}$ Statin therapy is established as first-line management for lowering LDL-c and significantly reduces the incidence of cardiovascular mortality, with more intense reductions in LDL-c resulting in additional cardioprotective benefits. It has been reported by Baigent et al, 2010 that for every $1 \mathrm{mmol} / \mathrm{L}$ reduction in LDL-c, there are significant reductions in all-cause mortality (12\%), myocardial infarction and coronary disease (23\%), and fatal or non-fatal strokes $(17 \%){ }^{2}$

Statins are generally considered safe and well tolerated but there are large cohorts of patients who are intolerant of the doses used to reduce LDL-c. ${ }^{3}$ The discontinuation of statin therapy after commencement is high and has been shown to be nearly $60 \%$ in the two-year period following an acute coronary syndrome (ACS) ${ }^{4}$. The majority of statin intolerance is attributed to muscle-related adverse events but the size of this effect does not explain the level of nonadherence to therapy. ${ }^{3}$ Intolerant patients experience myocardial infarctions up to $40 \%$ more frequently than patients adherent to high-intensity statin therapy $(80 \mathrm{mg}$ atorvastatin or $20 \mathrm{mg}$ rosuvastatin $)^{5}$. Non-adherence is complex and can include the fear of adverse effects, drug intolerance, poor follow-up by healthcare providers, and a lack of education or perception of benefits. ${ }^{6}$ Above all, patients who fail to sufficiently reduce their LDL-c remain at risk of hyperlipidaemia as mentioned above and thus require consideration for alternative therapies.

Proprotein convertase subtilisin/kexin type 9 (PCSK9) inhibitors are a promising therapeutic option for patients with either intolerance or poor response to high intensity statin therapy including after optimisation with ezetimibe. Two human monoclonal antibodies to PCSK9 (alirocumab and evolocumab) are currently licenced and have been shown to significantly 
reduce LDL-c concentrations (average reduction of $3.15 \mathrm{mmol} / \mathrm{L}$ to $1.3 \mathrm{mmol} / \mathrm{L}$ ), when used alone or in conjunction with maximum tolerated statin therapy (defined as the maximum licensed or tolerated dose required to achieve a reduction in LDL-c greater than $50 \%$ from baseline) ${ }^{7,8}$ FOURIER (Further Cardiovascular Outcomes Research With PCSK9 Inhibition in Patients With Elevated Risk) trials demonstrated a reduction in LDL-c when evolocumab was added to statin therapy. ${ }^{9}$ In this study, the addition of evolocumab to statin therapy significantly reduced the risk of cardiovascular events, myocardial infarction (MI) and stroke, reducing the risk of death by approximately $15 \% .{ }^{9}$ Importantly, evolocumab caused no adverse effects as discontinuation rates were similar between treatment and placebo groups (both approximately $5 \%$ per year). ${ }^{10,11}$

Alirocumab and evolocumab are now recommended as a treatment option for primary hypercholesterolemia by the National Institute for Health and Care Excellence (NICE) in patients identified as 'high risk' (in whom LDL-c $>4 \mathrm{mmol} / \mathrm{L}$ ) or 'very-high risk' (in whom LDL-c $>3.5 \mathrm{mmol} / \mathrm{L}$ ) of further cardiovascular events (Table 1), despite maximal tolerated lipid-lowering therapy. ${ }^{12,13}$ The European Society of Cardiology/European Atherosclerosis Society (ESC/EAS) suggest that alirocumab and evolocumab should be considered in patients with clinical atherosclerotic cardiovascular disease (ASCVD) and an LDL-c > $3.6 \mathrm{mmol} / \mathrm{L}$, despite maximally tolerated statin therapy (with or without ezetimibe), statin intolerance, or LDL-c values $>2.6$ if additional indices of risk severity are present (e.g. diabetes with organ damage, repeated ACS, and ischaemic stroke). ${ }^{14,15-18}$ Data documenting the number of patients for whom alirocumab and evolocumab are an option under current scientific society guidance remains sparse. In this study, we aimed to estimate the proportion of patients following an MI in the real world setting who could be considered for alirocumab and evolocumab therapy based on lipid levels from current NICE guidance. 


\begin{tabular}{|l|l|l|}
\hline \multicolumn{1}{|c|}{ Without CVD } & \multicolumn{3}{|c|}{ With CVD } \\
\hline & $\begin{array}{l}\text { 'High risk' of CVD (history of 'Very-high risk' of CVD } \\
\text { ACS, coronary or other arterial } \\
\text { revascularisation procedures; } \\
\text { coronary heart disease; } \\
\text { (recurrent } \\
\text { events or cardiovascular events } \\
\text { in more than one vascular bed } \\
\text { (poly-vascular disease) } \\
\text { arterial disease). }\end{array}$ \\
\hline $\begin{array}{l}\text { Not recommended at } \\
\text { any } \\
\text { concentration }\end{array}$ & $\begin{array}{l}\text { Recommended only if LDL-c } \\
\text { concentration is persistently } \geq \\
4.0 \mathrm{mmol} / \mathrm{L}\end{array}$ & $\begin{array}{l}\text { Recommended only if LDL-c } \\
\text { concentration is persistently } \geq \\
3.5 \text { mmol/L }\end{array}$ \\
\hline
\end{tabular}

Table 1. LDL-c thresholds for primary non-familial hypercholesterolemia or mixed hyperlipidaemiaintenis above which evolocumab is recommended (NICE). ${ }^{12,13}$

\section{METHODS}

The aim of this study was to understand lipid management in patients following an acute MI in a UK real world setting post CG $181^{19}$ and to estimate the proportion of patients who may be considered for therapy with PCSK9 inhibitors in the context of current NICE crtieria. ${ }^{19}$ The primary outcome was to ascertain the proportion of patients who are likely to satisfy the eligibility criteria for PCSK9 inhibitors post-MI using NICE lipid criteria. Secondary outcomes included the proportion of patient's post-MI satisfying the lipid-lowering targets stated within NICE, and an estimation of the proportion of patients failing to meet eligibility for PCSK9 inhibitors that require escalation of lipid-lowering therapy despite receiving the maximum tolerated statin therapy (i.e Atorvastatin 40-80 mg or Rosuvastatin 20-40 mg).

Electronic clinical records of all patients admitted with ST-elevation MI (STEMI) or non-ST elevation MI (NSTEMI) to the Cardiology Departments at two large university teaching hospitals in Merseyside, UK (Aintree University Hospital, Liverpool, UK; Whiston Hospital, Prescot, UK) between $1^{\text {st }}$ March 2015 and the $31^{\text {st }}$ October 2015 were analysed. Data for each patient included: patient demographics, date of admission, admission lipid profiles (fasting or non-fasting), lipid lowering medications on admission (including dose), lipid lowering 
medications at discharge, date of follow-up, lipid profile and history of CVD (to classify patients as 'high risk' or 'very-high risk' of future cardiovascular events). Variations in lipid and lipoprotein levels after acute MI manifest within 24 to $48 \mathrm{~h}$ following the onset of chest pain (termed the acute phase response). In situations where LDL-c values were not available, but total cholesterol and High-Density Lipoproteins (HDL) were recorded, LDL-c values were calculated using the externally validated formula: LDL-c $=3 / 4(\mathrm{TC}-\mathrm{HDL}-\mathrm{c}) \cdot{ }^{20}$ Patients were excluded from analysis if the post-intervention lipid profiles were not recorded or unavailable. In circumstances where multiple post-intervention (high-intensity statin therapy) lipid profiles were measured, the value closest to three months post-admission was used for analysis, in-line with NICE recommendations relating to the timeliness of high-intensity statin follow-up to monitor treatment efficacy. ${ }^{19}$

According to NICE guidelines, 'high risk' patients (Table 1) are eligible for PCSK9 inhibitor therapy if LDL-c is persistently above $4 \mathrm{mmol} / \mathrm{L}$, despite maximal tolerated lipid-lowering therapy. Similarly, 'very-high risk' patients (Table 1) are eligible for therapy if LDL-c is persistently above $3.5 \mathrm{mmol} / \mathrm{L}$. Within this study, if a patient was identified with an LDL-C > $4 \mathrm{mmol} / \mathrm{L}$ in 'high risk' patients (or $>3.5 \mathrm{mmol} / \mathrm{L}$ in 'very-high risk' patients) on two separate occasions (at least 3 months apart) whilst adhering to maximum tolerated statin therapy, they were classified as 'eligible' for treatment with PCSK9 inhibitors.

Following an MI, patients that achieved at least a $40 \%$ reduction of non-HDL-c were defined as patient's post-MI meeting lipid-lowering targets from high-intensity statin therapy. The proportion of patients failing to achieve this reduction despite maximum tolerated statin therapy, who did not meet the eligibility criteria for PCSK9 inhibitor treatment were classified as 'requiring escalation of lipid-lowering therapy'. 


\section{RESULTS}

Between the $1^{\text {st }}$ March 2015 and the $31^{\text {st }}$ October 2015, 596 patients across both sites were admitted with acute MI. Of these patients, 366 were male (61.4\%), with an average age of 69.3 years (SD 12.6), and 230 were female (38.6\%), with an average age of 74.2 years (SD 12.9) (Table 2).

\begin{tabular}{|c|c|}
\hline & n $(\%)$ \\
\hline \multicolumn{2}{|l|}{ Patient demographics } \\
\hline Patient number & 596 \\
\hline Average age (years) male/female & $69.3 / 74.2$ \\
\hline Male & $366(61.4)$ \\
\hline Female & $230(38.6)$ \\
\hline \multicolumn{2}{|l|}{ Lipid-lowering therapy at discharge } \\
\hline Atorvastatin $(80 \mathrm{mg})$ & $500(83.89)$ \\
\hline Atorvastatin $(10 \mathrm{mg})$ & $1(0.17)$ \\
\hline Atorvastatin (20mg) & $3(0.50)$ \\
\hline Atorvastatin (40mg) & $3(0.50)$ \\
\hline Simvastatin (20mg) & $3(0.50)$ \\
\hline Ezetimibe $(10 \mathrm{mg})$ & $3(0.50)$ \\
\hline No therapy & $83(13.93)$ \\
\hline \multicolumn{2}{|l|}{ Lipid values recorded at follow-up } \\
\hline Data available & $373(62.58)$ \\
\hline Missing data & $223(37.42)$ \\
\hline
\end{tabular}

Table 2. Patient demographics and lipid lowering therapies at hospital discharge following an ACS.

The majority of patients $(\mathrm{n}=500,84 \%)$ were discharged on atorvastatin $80 \mathrm{mg}$ daily and a further 10 patients (2\%) treated with a lower dose or alternative statin (Table 2). Nearly $15 \%$ of patients $(n=84 ; 13.94 \%)$ were discharged without any form of lipid lowering therapy. The majority of these patients were recorded as allergic $(n=25)$ or intolerant $(n=56)$ to statin therapy. Of the 500 patients discharged on atorvastatin $80 \mathrm{mg}$ daily, $323 \mathrm{had}$ at least two LDLc measurements taken at least 3 months apart (Table 3). Of these, 204 patients had full cardiovascular history data available. We identified 173 patients at 'high risk' of future 
cardiovascular events (defined as having a history of ACS) and 31 at 'very-high risk' (defined as having a history of recurrent cardiovascular events or cardiovascular events in more than one vascular bed). A large number of the patients discharged on atorvastatin $(n=119)$ had no cardiovascular history, but by the nature of their admission for ACS, were classified as 'high risk' for future cardiovascular events under NICE guidelines (Tables 4-6). ${ }^{19}$

\begin{tabular}{|c|c|}
\hline & n (\%) \\
\hline \multicolumn{2}{|c|}{ Lipid-lowering therapy on admission } \\
\hline No statin $(\%)$ & $127(25.4)$ \\
\hline Atorvastatin $(80 \mathrm{mg})$ & $51(10.2)$ \\
\hline Atorvastatin $(10 \mathrm{mg})$ & $9(1.8)$ \\
\hline Atorvastatin $(20 \mathrm{mg})$ & $11(2.2)$ \\
\hline Atorvastatin $(40 \mathrm{mg})$ & $39(7.8)$ \\
\hline Rosuvastatin (10mg) & $2(0.4)$ \\
\hline Rosuvastatin (20mg) & $1(0.2)$ \\
\hline Rosuvastatin (40mg) & $1(0.2)$ \\
\hline Simvastatin $(10 \mathrm{mg})$ & $3(0.6)$ \\
\hline Simvastatin $(20 \mathrm{mg})$ & $19(3.8)$ \\
\hline Simvastatin (40mg) & $21(4.2)$ \\
\hline Pravastatin $(10 \mathrm{mg})$ & $1(0.2)$ \\
\hline Pravastatin $(20 \mathrm{mg})$ & $1(0.2)$ \\
\hline Ezetimibe (10mg) & $2(0.4)$ \\
\hline Missing data & $212(42.4)$ \\
\hline \multicolumn{2}{|c|}{ Previous cardiovascular events } \\
\hline Yes ('very high-risk') & $51(10.2)$ \\
\hline No ('high-risk') & $237(32.8)$ \\
\hline Unknown & $212(57.0)$ \\
\hline \multicolumn{2}{|c|}{$\begin{array}{l}\text { Post-admission lipid profile measured (at least } 2 \text { values separated by a } \\
\text { least } 3 \text { months) }\end{array}$} \\
\hline Yes & $323(64.6)$ \\
\hline No & $177(35.4)$ \\
\hline
\end{tabular}

Table 3. Lipid lowering therapy, Lipid data availability and clinical risk status of patients admitted with a diagnosis of ACS $(n=500)$.

Of the 173 patients identified as high risk for future cardiovascular events, 127 (73.41\%) had LDL-c $<2 \mathrm{mmol} / \mathrm{L}$ and 44 (25.43\%) had LDL-c of 2-4 mmol/L. Two patients had LDL-c levels persistently $>4 \mathrm{mmol} / \mathrm{L}$ despite maximal statin therapy (1.16\%) (Table 4, Figure 1). Of 
the 31 patients identified as 'very-high risk' for future cardiovascular events, 14 had LDL-c < $2 \mathrm{mmol} / \mathrm{L}(45.16 \%)$ and $13(41.94 \%)$ had LDL-c concentrations of $2-3.5 \mathrm{mmol} / \mathrm{L}$. Four patients had LDL-c persistently > $3.5 \mathrm{mmol} / \mathrm{L}$ (12.90\%) (Table 5; Figure 1). Of the 119 patients with no cardiovascular data available (and classified as 'high-risk' on the grounds of their admission for ACS), 91 had LDL-c $<2$ mmol/L (76.47\%) and 27 (22.69\%) had LDL-c ranging from 2-4 mmol/L. A single patient had LDL-c levels persistently above $4.0 \mathrm{mmol} / \mathrm{L}(0.84 \%)$ (Table 6, Figure 1).

\begin{tabular}{|l|l|l|l|l|}
\hline $\begin{array}{l}\text { Lipid management in high-risk } \\
\text { patients post-MI }\end{array}$ & $\mathbf{n}$ & $\begin{array}{l}\text { LDL-c < 2 } \\
\text { mmol/L }\end{array}$ & $\begin{array}{l}\text { LDL-c 2 - 4 } \\
\text { mmol/L }\end{array}$ & $\begin{array}{l}\text { LDL-c > 4 } \\
\text { mmol/L }\end{array}$ \\
\hline $\begin{array}{l}\text { High risk (defined as history of ACS, } \\
\text { coronary or other arterial } \\
\text { revascularisation procedures; coronary } \\
\text { heart disease; ischaemic stroke; } \\
\text { peripheral arterial disease) (\%) }\end{array}$ & 173 & $127(73.41)$ & $44(25.43)$ & $2(1.16)$ \\
\hline
\end{tabular}

Table 4. Lipid management in 'high risk' patients as defined in NICE guidelines.

\begin{tabular}{|l|l|l|l|l|}
\hline $\begin{array}{l}\text { Lipid management in very-high risk } \\
\text { patients post-MI }\end{array}$ & $\mathbf{n}$ & $\begin{array}{l}\text { LDL-c }< \\
\mathbf{2} \\
\mathbf{m m o l} / \mathbf{L}\end{array}$ & $\begin{array}{l}\text { LDL-c 2 } \\
\mathbf{3 . 5} \mathbf{~ m m o l} / \mathbf{L}\end{array}$ & $\begin{array}{l}\text { LDL-c > 3.5 } \\
\mathbf{m m o l} / \mathbf{L}\end{array}$ \\
\hline $\begin{array}{l}\text { Very-high risk (defined as recurrent } \\
\text { cardiovascular events or cardiovascular } \\
\text { events in more than 1 vascular bed } \\
\text { (poly-vascular disease) (\%) }\end{array}$ & 31 & $\begin{array}{l}14 \\
(45.16)\end{array}$ & $13(41.94)$ & $4(12.90)$ \\
\hline
\end{tabular}

Table 5. Lipid management in very-high risk patient as defined in NICE guidelines.

\begin{tabular}{|l|l|l|l|l|}
\hline $\begin{array}{l}\text { Lipid management in post-MI } \\
\text { patients in whom risk level is } \\
\text { unknown }\end{array}$ & LDL < 2 & $\begin{array}{l}\text { LDL-c 2-4 } \\
\mathbf{m m o l} / \mathbf{L}\end{array}$ & $\begin{array}{l}\text { LDL-c > 4 } \\
\text { mmol/L }\end{array}$ \\
\hline $\begin{array}{l}\text { At least high-risk (due to experiencing } \\
\text { MI), but unknown cardiovascular } \\
\text { history. }(\%)\end{array}$ & 119 & $91(76.47)$ & $27(22.69)$ & $1(0.84)$ \\
\hline
\end{tabular}

Table 6. Lipid management in patients in which the risk level was unknown. 
Of the patients admitted without any form of lipid lowering therapy and subsequently discharged on atorvastatin $80 \mathrm{mg},(\mathrm{n}=59)$, the average reduction in non-HDL cholesterol was $33.4 \%$ (SD 22.2\%). Nearly 50\% of participants failed to achieve the recommended reduction following the initiation of atorvastatin $80 \mathrm{mg}$ therapy post-MI $(\mathrm{n}=28,47.5 \%)$ (Table 7$)$.

\begin{tabular}{|c|c|c|c|}
\hline & $\begin{array}{l}\text { No statin } \\
\text { therapy at } \\
\text { admission }\end{array}$ & $\begin{array}{l}\text { Low or medium } \\
\text { dose statin } \\
\text { therapy at } \\
\text { admission }\end{array}$ & $\begin{array}{l}\text { Atorvastatin } \\
(80 \mathrm{mg}) \text { at } \\
\text { admission }\end{array}$ \\
\hline \multicolumn{4}{|l|}{ Patient demographics } \\
\hline Patient number & 59 & 64 & 23 \\
\hline Average age (years) & $70.45($ SD 11.41) & $69.31(\mathrm{SD} 11.01)$ & 72.65 (SD 9.99) \\
\hline Male (\%) & $23(38.98)$ & $25(42.37)$ & $18(78.26)$ \\
\hline Female (\%) & $36(61.02)$ & $34(57.63)$ & $5(21.74)$ \\
\hline \multicolumn{4}{|c|}{ Admission } \\
\hline Mean non-HDL-c (mmol/L) & $3.76($ SD 0.98$)$ & 3.01 (SD 1.07) & 3.1 (SD 1.29) \\
\hline Mean LDL-c (mmol/L) & $3.04(\mathrm{SD} 0.96)$ & $2.37(\mathrm{SD} 0.98)$ & $2.20($ SD 0.82$)$ \\
\hline \multicolumn{4}{|c|}{ Follow-up } \\
\hline $\begin{array}{l}\text { Average time to follow-up } \\
\text { (months) }\end{array}$ & $9.99(\mathrm{SD} 5.65)$ & $9.05(5.40)$ & $12.15(6.48)$ \\
\hline Mean non-HDL-c (mmol/L) & $2.41(\mathrm{SD} 0.76)$ & $2.23(\mathrm{SD} 0.71)$ & $3.21(\mathrm{SD} 1.06)$ \\
\hline $\begin{array}{l}\text { Mean reduction in non-HDL- } \\
\text { c }(\mathrm{mmol} / \mathrm{L}) \%\end{array}$ & $33.40($ SD 22.2) & 22.73 (SD 19.04) & $\begin{array}{c}-10.01(\mathrm{SD} \\
27.69) \\
\end{array}$ \\
\hline $\begin{array}{l}\text { Number achieving >40\% } \\
\text { reduction in non-HDL-c }(\%)\end{array}$ & $31(52.54)$ & $14(21.89)$ & $1(4.35)$ \\
\hline Mean LDL-c (mmol/L) & $1.78($ SD 0.71$)$ & $1.62(\mathrm{SD} 0.60)$ & $2.39(\mathrm{SD} 0.88)$ \\
\hline $\begin{array}{l}\text { LDL-c < } 2 \mathrm{mmol} / \mathrm{L} \text { [No of } \\
\text { participants }](\%)\end{array}$ & $42(71.19)$ & $49(76.56)$ & $8(34.78)$ \\
\hline $\begin{array}{l}\text { LDL-c } 2-4 \mathrm{mmol} / \mathrm{L} \text { [No of } \\
\text { participants }](\%)\end{array}$ & $17(28.8)$ & $13(20.31)$ & $14(60.87)$ \\
\hline $\begin{array}{l}\text { LDL-c > } 4 \mathrm{mmol} / \mathrm{L} \text { [No of } \\
\text { participants }](\%)\end{array}$ & $0(0)$ & $1(1.56)$ & $1(4.35)$ \\
\hline
\end{tabular}

Table 7. Lipid profiles at admission and follow-up in patients discharged on $80 \mathrm{mg}$ atorvastatin for which admission and follow-up data was available. 


\section{DISCUSSION}

NICE has based its recommendations for PCSK9 inhibitor administration on the analysis of cost-effectiveness in the UK, the observed reduction of LDL-c in PCSK9 inhibitor trials, modelled risk reductions with therapy, and derivation of the corresponding ICERs expressed in cost per QALY. In this multi-centre study, at least $2.17 \%$ of patients would be deemed eligible for PCSK9 inhibitors post-MI according to NICE lipid criteria. These included $1.24 \%$ of very-high risk patients having LDL-c persistently above $3.5 \mathrm{mmol} / \mathrm{L}$ and $0.93 \%$ of high-risk patients having LDL-c above $4.0 \mathrm{mmol} / \mathrm{L}$ despite maximum statin therapy. We found that $29.1 \%$ of patients failed to have their LDL-c controlled to below $2 \mathrm{mmol} / \mathrm{L}$ but did not reach the NICE benchmark values for PCSK9 inhibitor eligibility, despite receiving statin therapy. This sizeable cohort represents a group of “in limbo' patients in which statin therapy fails to achieve sufficient LDL-c reductions, but LDL-c is not sufficiently elevated under NICE criteria to warrant PCSK9 inhibitor treatment. This group of patients would invariably benefit from optimisation of their lipid therapy by addition of Ezetimibe if tolerated or the direct addition of PCSK9 inhibitors for which at present they remain ineligible. Although not included in the NICE criteria, the question of how post-MI patients who are intolerant or allergic to statin therapy should be managed remains uncharacterised. Such patients represent a sizeable proportion of our study cohort (13.6\%), that remain at a high-risk of suffering adverse outcomes relating to hyperlipidaemia.

Zamora et al, 2018 investigated which patients would be eligible for PCSK9 inhibitors using scientific society guidance including estimating eligibility against NICE guidance for the secondary prevention of CVD. ${ }^{16}$ It was found that for optimised patients (defined as lipid lowering of $>50 \%$ and an adherence of $>80 \%$ ), $0.7 \%$ of patients were eligible. Additionally, $7.5 \%$ of patients not receiving lipid-lowering therapy were eligible under NICE guidance ${ }^{16,19}$ Upon comparison to the criteria of scientific societies, NICE was identified as the most 
stringent. For example, in accordance with the European Society of Cardiology / European Atherosclerosis Society (ESC/EAS) guidance in the same patient cohort, $5.1 \%$ and $16.2 \%$ of patients, respectively, were deemed eligible. This was dependent on the patients previously receiving optimal lipid-lowering therapy. ${ }^{14,16}$

The clinical effectiveness of PCSK9 inhibitors is widely accepted and described as the most important risk-reducing therapy since the advent of statins ${ }^{21,22}$. The major barrier to their widespread use is cost and availability. The US list price of Evolocumab is $\$ 14,000$ a year, which would require a reduction of nearly $70 \%$ to $\$ 4124$, to achieve a cost-effectiveness threshold of $\$ 100,000$ per quality-adjusted life year (QALY) ${ }^{23}$. In the UK, the list price of evolocumab is lower at $£ 4,383$ per annum, but the cost-effectiveness threshold is applied by NICE ${ }^{24}$. Importantly, the effects of PCSK9 inhibitors on LDL-c and the associated reduction in cardiovascular risk is meaningless to patients unable to access this medication due to cost.

Kazi et al. ${ }^{25}$ applied the established Cardiovascular Disease Policy Model (CDPM) to project the clinical and economic consequences of PCSK9 inhibitors in addition to statins for the secondary prevention of CVD. They modelled the reduction in LDL-c levels as reported by short-term studies of PCSK9 inhibitors, and assumed that lowering LDL-c would reduce coronary heart disease to the same extent as reported in pooled data from large RCTs of statins: a relative risk of 0.76 per $\mathrm{mmol} / \mathrm{L}$ reduction in LDL-c. They also assumed that PCSK9 inhibitors would continue to be effective for the patient's lifetime, at a cost of $\$ 14,350$ per annum. It was projected that the use of PCSK9 inhibitors for 5 years in all US adults for whom they are indicated would total $\$ 592$ billion in drug spending, offset against $\$ 28$ billion in averted cardiovascular events ${ }^{24}$. The published results suggest that the cost per QALY for PCSK9 inhibitors added to statins for the secondary prevention of CVD would be $\$ 316,000$ per QALY ${ }^{21}$. Thus, the cost-effectiveness of PCSK9 inhibitors do not meet accepted benchmarks for good value at present. $^{24}$ 
This study had a number of limitations. Firstly, of the 596 patients admitted over both sites, only 323 of the 500 patients discharged on atorvastatin had at least two LDL-c values measured at least 3 months apart (64.6\%). Furthermore, of those discharged on atorvastatin, only 204 patients $(63.2 \%)$ had full data available on their previous cardiovascular events. This limited the ability to upgrade a patient from being classified as high risk for subsequent cardiovascular events, to being classified as very-high risk. This may have led to an underestimation of the patients eligible for PCSK9 inhibitor therapy under NICE criteria (Table 1). ${ }^{19}$ Secondly, no data was collected on the adherence to therapy; and as such, it is impossible to determine whether patients adhered to the lipid-lowering therapeutic regimen, which has the potential to exaggerate the number of patients eligible for PCSK9 inhibitor therapy. Thirdly, once patients were discharged from secondary care, the lipid management responsibility falls on the primary care physicians. This has the potential to impact both the long-term monitoring of the response to therapy and the educational needs of patients.

To our knowledge, this is the first study to estimate the proportion of patients following ACS who are eligible for PCSK9 inhibitor therapy in accordance with NICE criteria. We importantly reveal a significant proportion of high-risk patients to whom PCSK9 inhibitors would be beneficial. This cohort of patients in which the response to maximum tolerated lipid-lowering therapy is inadequate by NICE aims (reduction in non-HDL-c $>40 \%$ following the introduction of high dose statin therapy), do not reach the NICE targets for PCSK9 inhibitor treatment. An issue therefore remains as to how patients these patients are managed. Until the costs of alirocumab and evolocumab are reduced by pharmaceutical companies and healthcare providers, their true benefits to the large groups of patients who would benefit from their administration are yet to be observed. Current studies show that combining statin therapy with ezetimibe can promote the dual inhibition of both cholesterol production and absorption. Until PCSK9 inhibitors become more readily available, using this combination to achieve lower 
serum cholesterol levels and more optimised lipid levels in post-MI patients is likely to be the only option at the moment, with single agent ezetimibe and or possibly in combination with lower doses of statins to circumvent the problem of statin intolerance. 


\section{Figure legends}

Figure 1: Number of patients post MI as per patient risk group and their LDLc levels. The figures are derived from NICE guidance for patients who are eligible for PCSK9. Groups are divided to very high, high and unknown risk (but at least high due to MI). 


\section{REFERENCES}

1. Ference BA, Ginsberg HN, Graham I, Ray KK, Packard CJ, Bruckert E, et al. Lowdensity lipoproteins cause atherosclerotic cardiovascular disease. 1. Evidence from genetic, epidemiologic, and clinical studies. A consensus statement from the European Atherosclerosis Society Consensus Panel. Eur Heart J [Internet]. 2017

2. Baigent C, Blackwell L, Emberson J, Holland LE, Reith C, Bhala N, et al. Efficacy and safety of more intensive lowering of LDL cholesterol: A meta-analysis of data from 170 000 participants in 26 randomised trials. Lancet. 2010;376(9753):1670-81.

3. Banach M, Rizzo M, Toth PP, Farnier M, Davidson MH, Al-Rasadi K, et al. Statin intolerance - An attempt at a unified definition. Position paper from an International Lipid Expert Panel. Arch Med Sci. 2015;11(1):1-23.

4. Jackevicius CA, Mamdani M, Tu J V. Adherence With Statin Therapy in Elderly Patients With and Without Acute Coronary Syndromes. JAMA [Internet]. 2002;288(4):462-7.

5. Serban M-C, Colantonio LD, Manthripragada AD, Monda KL, Bittner VA, Banach M, et al. Statin Intolerance and Risk of Coronary Heart Events and All-Cause Mortality Following Myocardial Infarction. J Am Coll Cardiol [Internet]. 2017;69(11):1386-95.

6. Banach M, Stulc T, Dent R, Toth PP. Statin non-adherence and residual cardiovascular risk: There is need for substantial improvement. Vol. 225, International Journal of Cardiology. 2016. p. 184-96.

7. Sabatine MS, Giugliano RP, Wiviott SD, Raal FJ, Blom DJ, Robinson J, et al. Efficacy and Safety of Evolocumab in Reducing Lipids and Cardiovascular Events. N Engl J Med [Internet]. 2015;372(16):1500-9. 
8. Robinson JG, Farnier M, Krempf M, Bergeron J, Luc G, Averna M, et al. Efficacy and Safety of Alirocumab in Reducing Lipids and Cardiovascular Events. N Engl J Med [Internet]. 2015;372(16):1489-99.

9. Ference B, Cannon C, Landmesser U, Lüscher T, Catapano A, Ra K. Reduction of low density lipoprotein-cholesterol and cardiovascular events with proprotein convertase subtilisin-kexin type 9 (PCSK9) inhibitors and statins: an analysis of FOURIER, SPIRE, and the Cholesterol Treatment Trialists Collaboration. Eur Hear J. 2017;0:1-6.

10. Zhang XL, Zhu QQ, Zhu L, Chen JZ, Chen QH, Li GN, et al. Safety and efficacy of anti-PCSK9 antibodies: A meta-analysis of 25 randomized, controlled trials. BMC Med. $2015 ; 13(1)$.

11. Navarese E, Kołodziejczak M, Schulze V. Effects of proprotein convertase subtilisin/kexin type 9 antibodies in adults with hypercholesterolemia: a systematic review and meta-analysis. Ann Intern Med. 2015;163(1):40-51.

12. National Institute for Health and Care Excellence. Alirocumab for treating primary hypercholesterolaemia and mixed dyslipidaemia [Internet]. 2016.

13. National Institute for Health and Care Excellence. Evolocumab for treating primary hypercholesterolaemia and mixed dyslipidaemia [Internet]. 2016.

14. Catapano AL, Graham I, Backer G De, Wiklund O, Chapman MJ, Drexel H, et al. 2016 ESC/EAS Guidelines for the Management of Dyslipidaemia. Eur Heart J. 2016;37(39):2999-3058.

15. Stoenkenbroek RM, Hartgers M, Rutte R, de Wijer D, Stroes E, Hovingh G. PCSK9 inhibitors in clinical practice: Delivering on the promise? Atherosclerosis. 2018;270:205-10. 
16. Zomora A, Masana L, Comas-Cufi M, Plana N, Vila A, Garcia-Gil M, et al. Number of Patients Eligible for PCSK9 Inhibitors Based on Real-world Data From 2.5 Million Patients. Rev Esp Cardiol. 2018;

17. Rane PB, Patel J, Harrison DJ, Shepherd J, Leith A, Bailey H, et al. Patient Characteristics and Real-World Treatment Patterns Among Early Users of PCSK9 Inhibitors. Am J Cardiovasc Drugs. 2018;18(2):103-8.

18. Saborowski M, Dölle M, Manns MP, Leitolf H, Zender S. Lipid-lowering therapy with pcsk9-inhibitors in the management of cardiovascular high-risk patients: Effectiveness, therapy adherence and safety in a real world cohort. Cardiol J. 2018;25(1):32-41.

19. NICE. Lipid modification: NICE guideline (CG181). Natl Inst Heal Clin Excell. 2014;12(July):231-54.

20. de Cordova CMM, de Cordova MM. A new accurate, simple formula for LDLcholesterol estimation based on directly measured blood lipids from a large cohort. Ann Clin Biochem. 2013;50(1):13-9.

21. Hlatky MA, Kazi DS. PCSK9 Inhibitors: Economics and Policy. Vol. 70, Journal of the American College of Cardiology. 2017. p. 2677-87.

22. Giacomo Pucci, Arrigo F Cicero, Claudio Borghi \& Giuseppe Schillaci. Emerging biologic therapies for hypercholesterolaemia, Expert Opinion on Biological Therapy, 17:9, 1077-1087.

23. Arrieta A, Page TF, Veledar E, Nasir K. Economic evaluation of PCSK9 inhibitors in reducing cardiovascular risk from health system and private payer perspectives. PLoS One. $2017 ; 12(1)$.

24. McGettigan P, Ferner RE. PCSK9 inhibitors for hypercholesterolaemia. BMJ (Online). 
$2017 ; 356$.

25. Kazi DS, Moran AE, Coxson PG, Penko J, Ollendorf DA, Pearson SD, et al. Costeffectiveness of PCSK9 Inhibitor Therapy in Patients With Heterozygous Familial Hypercholesterolemia or Atherosclerotic Cardiovascular Disease. JAMA [Internet]. 2016;316(7):743. 


\section{Author contributions}

All persons who meet authorship criteria are listed as authors, and all authors certify that they have participated sufficiently in the work to take public responsibility for the content, including participation in the concept, design, analysis, writing, or revision of the manuscript.

Furthermore, each author certifies that this material or similar material has not been and will not be submitted to or published in any other publication before its appearance in the Postgraduate Medical Journal.

Ahmed Elamin: Study Design, Data collection, Statistical Analysis, Manuscript Writing Ciaran Grafton-Clarke: Data Collection, Statistical Analysis, Contribution to Manuscript Kai Wen Chen: Data collection; Toba Obafemi: Data Collection; Ahai Luvai: Proof Reading; Ravish Katira: Study Design, Proof Reading; Gershan Davis: Study Design, Proof Reading. 
Main messages of the article (Real world data show that post CG181 guidance): -

- Most post MI patients (84\%) are discharged on Atorvastatin $80 \mathrm{mg}$ daily.

- Approximately $50 \%$ of statin naive MI patients achieve a $>40 \%$ reduction in non-HDL-c with Atorvastatin $80 \mathrm{mg}$ daily.

- Approximately $30 \%$ of statin naïve MI patients prescribed Atorvastatin 80mg would have an LDL $>2 \mathrm{mmol} / \mathrm{L}$ on follow up post MI.

- Similarly, $30 \%$ of all post MI patients have an LDL $>2 \mathrm{mmol} / \mathrm{L}$ on follow up but do not meet NICE lipid level criteria for pcsk9 prescription.

- $15 \%$ of post MI patients are discharged on no statin therapy, being defined as allergic or intolerant. 


\section{Remaining unanswered questions:}

- How should 'statin intolerant" patients be optimally managed?

- How could the use of Ezetimibe be increased in the care of the post MI patient?

- Should cardiac rehabilitation programs be more involved in addressing patient selfmanagement, appropriate prescribing and good lipid control in these high risk patients? 